\title{
Comparison of Partograms for Spontaneous and Induced
}

\section{Labour}

\author{
T Parijatha ${ }^{1}$, G Vijayabharathi ${ }^{2 *}$
}

1 \& 2 - Assistant Professor, Department of Obstetrics and Gynecology, Prathima Institute of Medical Sciences, Naganoor, Karimnagar.

Address for correspondence:Dr.Vijayabharati, Assistant Professor, Department of Obstetrics and Gynecology, Prathima Institute of Medical Sciences, Naganoor, Karimnagar, Telangana, India. Email:gv_bharathi236@gmail.com

DOI:10.47799/pimr.0902.10

Date of Submission: 11/1/2021

Date of Peer review :23/2/2021

Date of Acceptance: 4/03/2021

\begin{abstract}
Background: Labour is a unique experience in a normal woman's life. If it is prolonged and tedious it may produce a picture of mental anguish and physical morbidity. For the newborn child, prolonged labor will pose danger to its survival and subsequent neurological development. We in the current study tried to evaluate the use of partograms for spontaneous and induced labor in primi and multis para women.
\end{abstract}

Methods: A total of $n=150$ cases were studied, and this includes both primis and multigravidae attending Prathima Hospital. They were divided into 3 groups (groups A, B \& C) patients in normal true labor and those in whom induction was used. The induced group was again divided into those induced with PGE2 gel or oxytocin. The modified WHO partogram starts with $4 \mathrm{cms}$ cervical dilatation. partograms were plotted to assess the progress of labor in each group and analyzed.

Results: Group A for $52 \%$ primis and $64 \%$ multis the partogram fell before the alert line i.e. thedelivered before reaching the alert line, Group - B 56\% primis and 48\% multis in the partogrammoved between the alert and action lines. In GroupA $8 \%$ primis and $1 \%$ multis have reached orcrossed the action line. $12 \%$ primis and $1 \%$ multis in group-B have reached or crossed the actionline. $28 \%$ primis and $16 \%$ multis in group-C have reached or crossed the action line, Interventions like forceps delivery or cesarean section was done for those who have reached orcrossed the action line

Conclusion: Partogram is a useful Non-invasive tool for monitoring the progress of labor in both spontaneous and induced labor for primis and multis. The Maternal and Fetal outcome is extremely favorable when partographic monitoring is done in parturients. The partogram helps us to take up decisive interventions in the form of accelerating labor, instrumental vaginal delivery (outlet Forceps/ventouse), and cesarean section.

Key words: Partogram, Multi gravida, primigravida, labor induction

\section{INTRODUCTION}

Labour is a dynamic process, that expels the products of conception at or near term. Ourresponsibility as obstetricians has become critical in providing a healthy mother with an undamaged healthy child. Labour is characterized by a progressive increase in frequency, intensity, and duration of uterine contractions, progressive effacement and dilatation of the cervix, andprogressive descent of the fetus through the birth canal.Five lakhs of women die every year in the world because of pregnancyand childbirth. Every minute of every day a woman dies of pregnancy-relatedcomplications. ${ }^{[1]}$ Maternal mortality remains one of the major problems in publichealth today, especially in developing countries, where maternal mortality is estimated to be 550 for $1,00,000$ live births, which is 100 times higher than indeveloped countries. Causes of maternal mortality according to WHO are unsafeabortion $13 \%$, sepsis $15 \%$, obstructed labor $8 \%$, and hypertensive disorders $12 \% .{ }^{[2]}$ when accompanied by appropriate provider knowledge and skills, practice guidelines, financing and distribution systems, and community support, technology-based solutionslike partograms, vacuum extraction, infection treatment, preeclampsia detection, etc cancontribute to a significant reduction in maternal morbidity and mortality around theworld. ${ }^{[1]}$ Labour has been termed the most dangerous journey a human ever undertakes. The reason is that although it is a natural process, complications canarise at any time during its course. Maternal mortality remains 
between 500:1 and 1000deaths for 100,000 live births in developing countries. ${ }^{[3]} \mathrm{A}$ major cause of these deathsis prolonged obstructed labor primarily because of cephalopelvic disproportion. In those who survive, morbidity is significant due to complications like sepsis, postpartum hemorrhage, ruptureduterus, and urinary fistula. Obstructed labor is also amajor precedent of perinatal deaths, birth asphyxia, and neonatal sepsis. Mostmaternal deaths and complications attributable to obstructed and prolonged labor could beprevented by cost-effective and affordable health interventions like the use ofpartograph. ${ }^{[1]} \mathrm{A}$ partograph is one of the valuable appropriate technologies in use forimproved monitoring of labor progress and maternal and fetal wellbeing. It is animportant tool for managing labor.This is through enabling nurses and doctors to record their examination findingson a standardized form, which generates a pictorial overview of labor progress, andmaternal and fetal condition, which allows for early identification and diagnosis ofpathological labor. Its use is critical in preventing maternal and perinatal morbidityand mortality and therefore has applicability in developed and developing worldsettings. ${ }^{[4]}$ Early detection of prolonged labor greatlycontributes to the preventionof obstructed labor and other related complications such as postpartum hemorrhage (PPH), ruptured uterus, puerperal sepsis, and obstetric fistula.The partograph provideshealth professionals with a pictorial overview of the labor to allow earlyidentification and diagnosis of the pathological labor. ${ }^{[5]}$ Therefore, proper use of a partograph in an environment where referral and timelyintervention are possible would greatly contribute to a reduction of maternal mortalityand morbidity in the region. Although the partograph is a simple and inexpensive tool which preventsmaternal deaths and complication due to obstructed or prolonged labor, it is not aswidely implemented as it should be.

\section{Material and methods}

This study was conducted in the Department of Obstetrics and Gynecology, Prathima Institute of Medical Sciences, Naganoor, Karimnagar. Institutional Ethical committee permission was obtained for the study. Written consent was obtained from all the participants of the study after explaining the nature of the study with expected outcomes in their local language. 150 low-risk cases admitted to Prathima Institute of Medical Sciences,Karimnagar were randomly selected for our study.

Inclusion criteria

1. Antenatal women $38-41$ weeks gestational age.

2. Single live fetus with cephalic presentation and with adequate fetal weight.

3. Subjects chosen for induction are low-risk cases.

4. No major or minor cepalopelvic disproportion.

Exclusion criteria

1. Less than 37 weeks gestational age.

2. History of bronchial asthma.

3. Malpresentation.

4. Multiple pregnancies.

5. Antepartum hemorrhage.

6. Active cardiac or Renal disease, PIH, Eclampsia, Gestational diabetes.

7. Previous intolerance to prostaglandins.

8. Grand multis.

9. High-risk cases for induction are also excluded.

A total of $n=150$ cases were studied, and this includes both primis and multigravidae attending prathima Hospital. They were dividedinto 3 groups (groups A, B \& C) i.e. patients in normal true labor and those in whominduction was used.The induced group was again divided into those induced with PGE2 gel oroxytocin. If any general or local complications were noted the cases were not selected.At the time of admission patients age, parity, gestational age, booking status, and ifbooked, investigations such as hemoglobin level, blood grouping, typing, urine albumin, sugar, and microscopic examination, and HIV, HBsAg, and VDRL were noted.The patient's pulse rate, blood pressure, the temperature wasrecorded, and a systemicexamination was carried out. A per abdominal examination was done and the height of the uterus, presentation, fetal heart rate was noted and per vaginal examination was done.The patients were divided into 3 groups

Table 1: Division of patients in 3 groups

\begin{tabular}{|c|c|c|}
\hline Group A & Patients induced with PGE2 gel & $\begin{array}{c}\text { Primis (25) } \\
\text { Multis (25) }\end{array}$ \\
\hline Group B & Patients induced with intravenous oxytocin infusion & Primis (25) \\
Multis (25)
\end{tabular}


In Group A,50 Patients ( 25 primis and 25 multis) in whom PGE2 gel was instilledinto the cervix were included. They were given $0.5 \mathrm{mg}$ of PGE2 gel to start with and itwas increased by $0.5 \mathrm{mg}$ every 6 hours if required upto a maximum of $1.5 \mathrm{mg}$ ( 3 doses) ifnecessary once the contractions are established and cervix $4 \mathrm{cms}$ dilated partogram wasplotted for monitoring the progress of labor (the modified WHO partogram starts with $4 \mathrm{cms}$ cervical dilatation i.e., the active phase of labor). In group B 50 Patients ( 25 primis and 25 multis) in whom induction was done withIV oxytocin infusion starting with 5 units of oxytocin in $500 \mathrm{ml}$ of ringerlactate at the rate of 5 milli units per minute for primis and 2.5 units of oxytocin for multigravidae. The dose wasincreased at the rate of 2.5 milli units every 20 minutes until effective uterine contractions areestablished 3 to 4 contractions each lasting for 40 seconds in every 10 minutes. Thereafterthe dose was maintained until delivery. A modified WHO Partogram was plotted for monitoringthe progress of labor. In group C, 50 patients (25 primis and 25 multis) in whom labor onset andprogress was spontaneous were monitored for the progress of labor using Modified WHOpartogram.Uterine contractions and fetal heart every 5 minutes in the second stage. Per vaginal examination was done every 2 hrs to assessthe progress. The patient's vitals rate were monitored every 15 minutes in the active phaseand

were monitored every 30 minutes. The duration of the active phase, rate of cervical dilatation, duration of the second stage, birth weight, APGAR of the baby, and thirdstage complications if any were noted.Induction was considered successful if the progress was satisfactory and the patientdelivered vaginally in the absence of maternal and fetal complications. In each group, ARM was done after the patient entered the active phase of labor(i.e., cervical dilatation was $4 \mathrm{~cm}$ ). Partograms (Modified WHO partograms) were plotted to assess the progress of labor.Statistical analysis was performed using statistical package for social sciences (SPSS) version 17.Descriptive statistics obtained included mean, standard deviation, and graphs.Inferential statistics performed included analysis of variants (Anova/ $f$ test) and $p$-values. If the $p$-value is $<0.05$ it means the Anova test performed and the $p$-value was significant. Postnatal mothers were monitored for $4 \mathrm{hrs}$ for any complications and the neonates werefollowed-up.

\section{Results}

A total of 150 low-risk patients admitted were randomly selected 50 patients each in Group A, B, and C (25 primis, 25 multis each), and the results were compared.In most of the patients, both primis and multis were in the 21 to 25 years age group (table 2 ).

Table 2:Age group and distribution of cases in three categories

\begin{tabular}{|c|c|c|c|c|c|c|}
\hline $\begin{array}{c}\text { Age range } \\
\text { (yrs) }\end{array}$ & \multicolumn{2}{|c|}{$\begin{array}{c}\text { Group A } \\
\text { (PGE2 gel) (n=50) }\end{array}$} & Group B & \multicolumn{2}{c|}{$\begin{array}{c}\text { Group C } \\
\text { (Oxytocin infusion) (n=50) }\end{array}$} \\
\hline & Primi (25) & Multi (25) & Primi (25) & Multi (25) & Primi (25) & Multi (25) \\
\hline$<20$ & $11(44 \%)$ & $1(4 \%)$ & $7(28 \%)$ & 0 & $12(48 \%)$ & 0 \\
\hline $21-25$ & $11(44 \%)$ & $14(56 \%)$ & $16(64 \%)$ & $13(52 \%)$ & $9(36 \%)$ & $14(56 \%)$ \\
\hline $26-30$ & $3(12 \%)$ & $10(40 \%)$ & $2(8 \%)$ & $12(48 \%)$ & $4(16 \%)$ & $11(44 \%)$ \\
\hline
\end{tabular}

The majority of the patients were in the 39 to 40 weeks, 41 weeks. The mean gestational weeks were $39.5 \pm 0.35$ (table gestational age group. The gestational range was from 37 to

3)

Table 3: Distribution of Gestational Age

\begin{tabular}{|c|c|c|c|c|c|c|}
\hline \multirow[t]{2}{*}{$\begin{array}{l}\text { Gestational Age } \\
\text { range (yrs) }\end{array}$} & \multicolumn{2}{|c|}{$\begin{array}{c}\text { Group } A \\
\text { (PGE2 gel) }(n=50)\end{array}$} & \multicolumn{2}{|c|}{$\begin{array}{c}\text { Group B } \\
\text { (Oxytocin infusion) }(n=50)\end{array}$} & \multicolumn{2}{|c|}{$\begin{array}{c}\text { Group C } \\
\text { (Spontaneous) }(n=50)\end{array}$} \\
\hline & Primi (25) & Multi (25) & Primi (25) & Multi (25) & Primi (25) & Multi (25) \\
\hline 37 to 38 & $3(12 \%)$ & $3(12 \%)$ & $5(20 \%)$ & $5(20 \%)$ & $5(20 \%)$ & $4(16 \%)$ \\
\hline 39 to 40 & $18(72 \%)$ & $19(76 \%)$ & $14(56 \%)$ & $18(72 \%)$ & $16(64 \%)$ & $18(72 \%)$ \\
\hline 41 to 41 & $4(16 \%)$ & $3(12 \%)$ & $6(24 \%)$ & $2(8 \%)$ & $4(16 \%)$ & $3(12 \%)$ \\
\hline
\end{tabular}

The Mean pre-induction modified bishop score is in pirmis -3 and in Multies -4 The Mean Post induction bishop score in primis 7,in Multies 8. post inductions score was less than 6 only in 1 case for which cesarean section was done.This

showsthat the efficacy of PGE2 gel in cervical ripening is good. The majority of the primis (52\%) required $1 \mathrm{mg}$ and most multis (64\%) required $0.5 \mathrm{mg}$ of PGE2 to establish effective uterine contractions. A lesser dose is required for Multis.0\% of the 
primis in Group A required $1.30 \mathrm{hrs}$ to $2.00 \mathrm{hrs}$ compared to group B in which $32 \%$ required $2.10 \mathrm{hrs}$ to $2.30 \mathrm{hrs}$ for peak onset of action. $60 \%$ of the multis in Group A and $48 \%$ of multi in Group B required 30 minutes to $1 \mathrm{hr}$. 32\% cases of primis in Group C required 1.3 to $2 \mathrm{hrs}$. $28 \%$ of cases of multis in group C required 1:3 to $2 \mathrm{hrs}$.The mean duration for peak onset of action in primis in group A and Group B were $1.24 \mathrm{hrs}$ and $2.30 \mathrm{hrs}$ respectively. Whereas multis it was almost the same $1.13 \mathrm{hrs}$ and 1.19 hrsrespectively. In primis, 20\% of cases required oxytocin augmentation and in multis, $12 \%$ of cases required oxytocin augmentation.The mean rate of cervical dilatation in Group A primis was $1.32 \mathrm{~cm} / \mathrm{hr}$ comparedto $1.27 \mathrm{~cm} / \mathrm{hr}$ in Group B and $1.20 \mathrm{~cm} / \mathrm{hr}$ in Group C.In Group A multis it was $2.32 \mathrm{~cm} / \mathrm{hr}$ as compared to $2.14 \mathrm{~cm} / \mathrm{hr}$ in Group B and $2.2 \mathrm{~cm} /$ hrin Group C.Cervical dilatation is faster in the PGE2 gel group compared to another group. And this isstatisticallysignificant $(P<0.001)$.

Table 4: progress of labor (group A, B \& C)

\begin{tabular}{|c|c|c|c|c|c|c|}
\hline $\begin{array}{c}\text { Gestational Age } \\
\text { range (yrs) }\end{array}$ & \multicolumn{2}{|c|}{$\begin{array}{c}\text { (PGE2 gel) } \\
(\mathrm{n}=50)\end{array}$} & \multicolumn{1}{c|}{$\begin{array}{c}\text { Oxytocin infusion) } \\
(\mathrm{n}=50)\end{array}$} & \multicolumn{2}{c|}{$\begin{array}{c}\text { Spontaneous) } \\
(\mathrm{n}=50)\end{array}$} \\
\hline & Primi (25) & Multi (25) & Primi (25) & Multi (25) & Primi (25) & Multi (25) \\
\hline Fallen beforealert line & $13(52 \%)$ & $16(64 \%)$ & $8(32 \%)$ & $12(48 \%)$ & $9(36 \%)$ & $11(44 \%)$ \\
\hline Moved in between alert and action line & $10(40 \%)$ & $8(32 \%)$ & $14(56 \%)$ & $12(48 \%)$ & $9(36 \%)$ & $10(40 \%)$ \\
\hline Reached or crossed action line & $2(8 \%)$ & $1(4 \%)$ & $3(12 \%)$ & $1(4 \%)$ & $7(28 \%)$ & $4(16 \%)$ \\
\hline
\end{tabular}

Group A for $52 \%$ primis and $64 \%$ multis the partogram fell before the alert line i.e. the

delivered before reaching the alert line, Group - B 56\% primis and $48 \%$ multis in the partogrammoved between the alert and action lines. In Group-A 8\% primis and 1\% multis have reached orcrossed the action line. $12 \%$ primis and $1 \%$ multis in group-B have reached or crossed the actionline. $28 \%$ primis and $16 \%$ multis in group-C have reached or crossed the action line, Interventions like forceps delivery or cesarean section were done for those who have reached orcrossed the action line (table 4).The mean duration of the active phase in Group A and Group B in primis was 5.09 hrs and5.31 hrs respectively whereas in multis it was $3.42 \mathrm{hrs}$ and $4.19 \mathrm{hrs}$ respectively, in group $\mathrm{C}-5.4 \mathrm{hr}$ in primis and $4.3 \mathrm{hr}$ in multis respectively.The duration of the active phase of labor is shorter in group A (PGE2 gel)compared to group B (oxytocin). And, it is shorter with induced labor compared tospontaneous labor. It is also shorter in multis compared to primis.The mean duration of the second stage was the same in both Groups A and $B$. Primis were 27.50 minutes and 28.50 minutes whereas it was 20.50 minutes and 23.26 minutes in multis inGroup A and Group B respectively. In group C 29.50 min and multis 24.20 minutes.

Table 5: Mode of delivery among the three groups

\begin{tabular}{|c|c|c|c|c|c|c|}
\hline \multirow{2}{*}{ Mode of Delivery } & \multicolumn{2}{|c|}{$\begin{array}{c}\text { Group A } \\
\text { (PGE2 gel) }(n=50)\end{array}$} & \multicolumn{2}{c|}{$\begin{array}{c}\text { Group B } \\
\text { (Oxytocin infusion) (n=50) }\end{array}$} & \multicolumn{2}{c|}{$\begin{array}{c}\text { Group C } \\
\text { (Spontaneous) (n=50) }\end{array}$} \\
\hline & Primi (25) & Multi (25) & Primi (25) & Multi (25) & Primi (25) & Multi (25) \\
\hline SVD & $17(68 \%)$ & $23(92 \%)$ & $16(64 \%)$ & $22(88 \%)$ & $17(68 \%)$ & $23(92 \%)$ \\
\hline Instrumental & $6(24.8 \%)$ & $2(8 \%)$ & $6(24 \%)$ & $3(12 \%)$ & $6(24 \%)$ & $2(8 \%)$ \\
\hline LSCS & $2(8 \%)$ & - & $3(12 \%)$ & - & $2(8 \%)$ & - \\
\hline
\end{tabular}

There was no significant difference in the mode of delivery among the three groups (Table 5). The birth weight was in the range of 2.5 to $3.0 \mathrm{kgs}$ in a majority of neonates ingroup-A and B, In Group-C, for primis, the birth weight for $48 \%$ of the neonates was inthe range of 2.5 to $3.0 \mathrm{kgs}$ and it was in the range of $3.1-3.5 \mathrm{kgs}$ for $44 \%$. and in multis $76 \%$ neonates had a birth weight in the range of 2.5 to 3.0 kgs. Hyperbilirubinemia incidence was more with group $B$ (oxytocin) in four cases outof which one required phototherapy for six days.One fetal death in the prostaglandin group was because of secondary apnoea. One death in the spontaneous group was because of undetected hydrocephalus for which cephalocentesiswas done and the baby died later.The side effects were the same except for $\mathrm{PPH}$ which was more in group $C$ and nil in groupA. Vomiting in group $A$ was due to the drug. Fever was present in all the groups and was notdue to the drug in groups A \& B but due to maternal infection. Uterine hyperstimulation in bothgroups was not severe enough to cause fetal distress in the neonate but it took a long time ingroup A subside. 


\section{Parijatha et al}

Discussion

The majority of the subjects of our study in all the 3 groups were $21-25$ years of age in both primis andmultis. We have excluded grand multis in our study because they are not suitable forinduction of labor due to the risk of hyperstimulation and uterine rupture. We

have selected term patients (from 37 completed weeks to 41 completed weeks) for ourstudy. The maternal and fetal risks associated with prematurity and preterm labor areautomatically excluded from our study, as also the maternal and fetal risks associatedwith post maturity (after 41 completed weeks). Initiation of normal labor as also theinduction of labor with drugs is done in subjects at term gestation to study theprogress of labor and to assess the maternal and fetal outcome. In our study, the meanpre-induction modified Bishops score was 3 for primis and 4 for multis and the postinductionscore was 7 for both primis and multis. The response to PGE2 gel is much better if thepre-induction Bishops score is less.In our study, it has taken on an average 6 to 9 hours for the change in Bishopsscore It has to be noted that PGE2 gel has more of cervical ripening effect primarily whichinturn induces labor by sensitizing oxytocin receptors in the myometrium.A study was done by Poornima et al; ${ }^{[6]}$ concluded that the preinduction cervicalscoring changes from unfavorable to favorable by 6 hours.The PGE2 gel has aphysiological effect on the cervix. The duration of labor in all the 3 groups was studied by us and we noted thatin group-A it was $5-6 \mathrm{hrs}$ in primis and 3-4hrs in multis. In group-B it was 6-8 hrs inprimis and $4-5 \mathrm{hrs}$ in multis. In group-C it was $7-9 \mathrm{hrs}$ in primis and 5 -6 hrs inmultis. This is shorter compared to Friedmann et al; ${ }^{[7]}$ This is because the ModifiedWHO partogram starts with $4 \mathrm{~cm}$ dilatation.Orji $\mathrm{E}^{[8]}$ who compared labor outcome in spontaneous and induced labor by using a modified WHO partogram,concluded that induced labor monitored with WHO partogram is comparative to spontaneous labor with no increased adverse maternal and fetal effects. The study of labor concluded that partogram was a gold standard for assessing the progress of labor, this study helped the investigators in finding differences between labors of nulliparous and multiparous and spontaneous and induced labor as done in our study.[9] Most of the studies in the literature have shown that the labor outcome is almost the same in spontaneous and induced labor, based on the pantographic analysis of labor.In our study, the majority of the primigravidae required $1 \mathrm{mg}$ of PGE2 gel andmost of the multis required $0.5 \mathrm{mg}$ of PGE2 gel in multis most of them required onlyone dose. Fawolle et al; [10]studied the influence of parity on the partographic management of labor in Nigerian Tertiary Hospital. There were $136(37.0 \%)$ primigravidae and $232(63.0 \%)$ multiparae. The two groups were similar in booking status andrisk level. Primigravidae had lower rates of spontaneous labor onset (78.7) and thus higher rates of induction labor (21.3\%) than multiparae $(p<0.05$; or $51,95 \% \mathrm{Cl})(0.28-0.93)$. Primigravidae presented at lower cervical dilation and had more frequent vaginal examination than multiparae. Asha $\mathrm{R}$ et al; ${ }^{[10]}$ in their study on the effect of Partograph on the First stage of Delivery concluded that using Partograph can decrease the number of Caesarean sectioned so it is very necessary to use Partograph for all the mothers at the time of delivery.

\section{Conclusion}

Partogram is a useful Non-invasive tool for monitoring the progress of labor inboth spontaneous and induced labor for primis and multis.The Maternal and Fetal outcome is extremely favorable when partographicmonitoring is done in parturients. The partogram helps us to take up decisive interventions in the form ofaccelerating labor, instrumental vaginal delivery (outlet Forceps/ventouse), andcesarean section.Labour induced with PGE2 gel is marginally superior to that with oxytocininfusion when all the parameters and objectively measurable outcomes are considered.Partographic monitoring of labor should be the ideally considered protocol forall low-risk and high-risk cases in the labor room of all tertiary hospitals andsecondary care centers. Hence, it is recommended that implementations of partograms should beencouraged in all hospitals at all levels.

\section{REFERENCES}

1. World Health Organization.Maternal health and safe motherhood program. World Health Organization partograph in management of labor. Lancet.1994;343:1399-04.

2. WHO. Maternal mortality. Available from https:// www.who.int/news-room/fact-sheets/detail/maternalmortality[last accessed on 14/01/2021]

3. Orji EO, Fatusi AA, Makinde NO, Adeyemi BA,Onwudiegwu $U$. Impact of Training on the use of Partograph on maternal and perinatal outcome in peripheral Health Centers. J. Turkish - German Gynecol Assoc 2007; 8(2): 148 - 152.

4. Iffat Javeed, Shereen Bhutta, Tabassum Shoaib. Role of partogram in preventing prolonged labor; J Pak Med Assoc. August 2007; 57: 8.

5. Swamy MallaiahKenchaveeriah, Kamal Prakash Patil, TainaGurudeep Singh. Comparison of two who partographs. A one-year randomized trial J TurkishGynaecolAssoc 2011; 12:31-4.

6. Poornima R Ranka, Alka S Gupt, Shashank V Paruleka Pre induction Cervical Ripening, An Easier And Safer Alternative - A Randomised Study Dept.of Obstetrics and Gynaecology Seth GS Medical College, KEM Hospital, Parel, Mumbai. Available from https://www.bhj.org.in/ journal/1999_4104_oct99/original_701.htm[last accessed on $20 / 01 / 2021]$ 
7. Friedman EA. Primigravid labor: Agraphic statistical analysis. Obstet Gynecol. 1955;6:567.

8. Yadav K, Monika Ranga, Ankur Nama. Comparative study of induced and spontaneous labor in nulliparous women using modified WHO partograph. Int J Reprod Contracept Obstet Gynecol. 2020;9(5):2014-2019.

9. Fawolle $\mathrm{AO}$ and Fadare O.: influence of parity on the partographic management of laborin a Nigerian tertiary hospital; Niger Post Grad Med J. 2008 Dec; 15(4):234-237.

10. Asha R Dalal, Ameya CP. The partograph in childbirth: An absolute essentiality or mere exercise? J ObstetGynaecol India 2018; 68(1): 3-14.

How to cite this article : T Parijatha, G Vijayabharathi. Comparison of Partograms for Spontaneous and Induced Labour. Perspectives in Medical Research 2021; 9 (2):43-48 DOI:10.47799/pimr.0902.10

Sources of Support: Nil, Conflict of interest: None declared 